\title{
Both N- and C-terminal Regions Contribute to the Assembly and Functional Expression of Homo- and Heteromultimeric Voltage-gated $\mathrm{K}^{+}$Channels
}

\author{
William F. Hopkins, Vasiliki Demas, and Bruce L Tempel \\ Geriatric Research Education and Clinical Center, Veterans Affairs Medical Center, Seattle, Washington 98108 and the \\ Departments of Medicine and Pharmacology, University of Washington School of Medicine, Seattle, Washington 98195
}

\begin{abstract}
The functional diversity of voltage-gated $K^{+}$channels may be partially determined by the mechanisms that permit or limit the assembly of molecularly diverse $\mathrm{K}^{+}$channel subunits. To determine possible amino acid sequence domains required for subunit assembly and expression, we have constructed $15 \mathrm{~N}$ - and C-terminal interstitial or truncation deletion mutations in mKv1.1 (MBK1), a mouse Shaker-like K+ channel. We injected Xenopus oocytes with cRNA encoding each of these mutants and coinjected each mutant CRNA with cRNA for wild-type mKv1.3, another mouse Shaker-like $\mathrm{K}^{+}$channel that can form heteromultimers with $\mathrm{mKv1.1.} \mathrm{We}$ found that the last five amino acids of the $C$-terminus of mKv1.1 contribute to functional expression by (1) rescuing the function of mutants with a large truncation of the C-terminus ( $\Delta 424-495)$, and (2) contributing to the slow inactivation kinetics (time constant of 2-3 sec) of wild-type mKv1.1 whole-cell $\mathrm{K}^{+}$currents. All C-terminal deletion mutants were able to express at least as heteromultimers with mKv1.3, suggesting that the $\mathrm{C}$-terminus is not required for channel assembly. In contrast, nine different interstitia! or truncation mutants in which part of a highly conserved, large (80-99 amino acid residues) domain within the $\mathrm{N}$-terminus had been deleted were unable to express either homomultimers or heteromultimers. The relatively small sizes and nonoverlapping distributions of the interstitial deletions enable us to suggest that the structural integrity of this entire $\mathrm{N}$-terminal domain is required for subunit assembly and functional expression of this and probably other Shaker-like $\mathrm{K}^{+}$channel proteins.
\end{abstract}

[Key words: potassium channel, subunit assembly, deletion mutant, oocyte, dendrotoxin, inactivation]

Several lines of evidence suggest that functional voltage-dependent $\mathrm{K}^{+}$channels are composed of four subunits. Sequence analysis of clones from the Shaker locus (Tempel et al., 1987; Kamb et al., 1988; Pongs et al., 1988; Schwarz et al., 1988) revealed that the predicted protein was analogous to one of the four

\footnotetext{
Received April 9, 1993; revised July 23, 1993; accepted August 13, 1993.

We thank Dr. M. Bosma for comments on the manuscript, and Anna Garmiles for expert technical assistance. Margaret Allen constructed pGEX-1.1 and pGEX1.3. DTX-I was purified by Troy Martin. The SphI site PCR mutagenesis was performed by Sharon Smart. This work was supported by grants from the Nationa Institutes of Health (NS27206 and HL44948) and the Department of Veterans Affairs.

Correspondence should be addressed to Bruce L Tempel, GRECC (182-B), VA Medical Center, Seattle, WA 98108.

Copyright (C) 1994 Society for Neuroscience $0270-6474 / 94 / 141385-09 \$ 05.00 / 0$
}

internally homologous domains in functional voltage-dependent sodium and calcium channel $\alpha$-subunits (Noda et al., 1984; Tanabe et al., 1987). Direct tests of subunit stoichiometry were provided by analysis of toxin block of one expressed Shaker clone (MacKinnon, 1991), and by construction of synthetic $\mathrm{K}^{+}$ channcls linking various numbers of subunit domains (Liman et al., 1992). However, the molecular mechanisms by which $\mathrm{K}^{+}$ channel subunits assemble to form channel complexes are not understood. These undefined mechanisms allow the assembly of identical $\mathrm{K}^{+}$channel subunits (homomultimers) into functional channels (Timpe et al., 1988), as well as the assembly of nonidentical subunits from the same gene subfamily (heteromultimers) (Christie et al., 1990; Isacoff et al., 1990; Ruppersberg et al., 1990). The combinatorial possibilities are apparently limited, however, since $\mathrm{K}^{+}$channel subunits from different gene subfamilies appear not to assemble when coexpressed in Xenopus oocytes (Covarrubias et al., 1991; Li et al., 1992).

These observations raise an important question regarding the primary structural requirements for $\mathrm{K}^{+}$channel subunit assembly and functional expression. All voltage-dependent $\mathrm{K}^{+}$channels are thought to consist of cytoplasmic $\mathrm{N}$ - and $\mathrm{C}$-terminal domains flanking a region consisting of six membranc-spanning domains and a pore region linked by small cytoplasmic or extracellular loops (Miller, 1991). At least one $\mathrm{K}^{+}$channel type, rKv2.1 (drk1), can assemble and function in Xenopus oocytes with truncations that delete major portions of the $\mathrm{N}$ - and C-termini (VanDongen et al., 1990), implying that the transmembrane domains with minimal flanking residues are sufficient to enable subunit assembly and function. Using truncation deletions, Li et al. (1992) identified an amino acid sequence domain, which is highly conserved within the Shaker subfamily of genes, consisting of 114 residues in a hydrophilic region of the $\mathrm{N}$-terminus of Shaker B (ShB) $\mathrm{K}^{+}$channel subunit that is required to bind to the full-length $\mathrm{ShB}$ polypeptide.

We have taken a functional approach to address the question $\mathrm{K}^{+}$channel subunit association and expression in Xenopus oocytes. We constructed a number of interstitial or truncation deletion mutants that together span major portions of the $\mathrm{N}$ and C-termini of mKvl.1 (Tempel et al., 1988), a mouse member of the Shaker subfamily. We then tested the ability of these mutants to form functional channels when injected alone (presumably by forming homomultimers) or following coinjection with wild-type $\mathrm{mKvl} .3$ (to allow formation of heteromultimers) (Chandy et al., 1990). We exploited the functional differences between these two Shaker-like channels to demonstrate that, indeed, wild-type mKv1.1 and mKv1.3 can form heteromul- 
timers with a probable subunit stoichiometry of four. We also found that interstitial deletion mutations that included a portion of a large domain within the $\mathrm{N}$-terminus of $\mathrm{mKv} 1.1$ could not form and express functional channels either as homomultimers or as heteromultimers with $\mathrm{mKv} 1.3$. These results taken together with those of Li et al. (1992) suggest that this N-terminal domain is required for the assembly of Shaker-like subunits into functional $\mathrm{K}^{+}$channels.

\section{Materials and Methods}

Generation of mutant cDNAs. Standard molecular techniques were used throughout. mKv1.1 (MBK1) and mKv1.3 (MK3) were cloned into an expression vector, pGEX, which contains plasmid sequences from pGem3Zf (Promega), 5 untranslated sequences from Xenopus $\beta$-globin, and a modified translational initiation region containing BglII, NcoI, and ApaI cloning sites (kind gift of D. Andrews, McGill University). For pGEX-1.1, the Ncol site was used to replace the $\beta$-globin initiation codon with that of $\mathrm{mKv} 1.1$. In pGEX-1.3, 36 base pairs (bp) of the 5 ' untranslated region endogenous to the $\mathrm{K}^{+}$channel gene were subcloned in to the BglII site of the pGEX vector. Mutants were generated in pGEX1.1 using the following techniques.

(1) Linker mutagenesis: pGEX-1.1 was digested using two unique restriction endonucleases, a synthetic oligonucleotide linker being used to reclose the plasmid. The oligonucleotide linkers were designed to provide compatible overhanging ends while maintaining the open reading frame. Specific oligonucleotide sequences ranged in size from 13 to 64 bases and are available by contacting the Tempel lab. As an example, mutant $\Delta 53-159$ was generated as follows: pGEX-1.1 was digested with BstBI and SacI, gel purified, and reclosed using a linker formed by annealing 23 base sense and 17 base antisense oligonucleotides. The linker contained AA48-52(FETQL) fused to AA160-163(PESS) and resulted in the deletion of AA53 to AA159. A similar strategy was used to construct mutants $\Delta 1-\mathrm{A}-31, \Delta 53-68, \Delta 53-104, \Delta 53-124, \Delta 53-159$, $\Delta 74-104, \Delta 111-124$, and $\Delta 111-159$. All oligonucleotides were synthesized by the Molecular Pharmacology Core (U.W.) or by the Molecular Biology Core (VAMC), both of which use ABI DNA synthesizers.

(2) Cut-and-close mutagenesis: pGEX-1.1 was digested with two enzymes, the resulting ends being enzymatically modified with Klenow enzyme or mung bean Nuclease before reclosure. These techniques were used to construct mutants $\Delta 1-\mathrm{G}-48$ and $\Delta 127-166$.

(3) Site-directed mutagenesis: pBS-1.1(9.4Sac), a subclone of pBS-1.1 that does not contain any $\mathrm{N}$-terminal sequences, was mutagenized using polymerase chain reaction (PCR) (Ito et al., 1991) in order to introduce a novel SphI site beyond the conserved transmembrane region. pBS$1.1(9.4 \mathrm{Sac} / \mathrm{Sph})$ was used in turn to generate a frame-shift mutation (by filling and reclosing) that replaces the original $3^{\prime}$ terminus of $\mathrm{mKv} 1.1$ with 10 nonsense amino acids followed by a stop codon (LSCSMLVLLT*) but does not truncate the transcript. The region from the BstXI site (in S4) to the end of this mutant subclone was used to replace the corresponding region in each of pGEX-1.1 and the previously constructed $\mathrm{N}$-terminal deletion mutant $\Delta 131-159$, thereby generating $\Delta 424-495$ and the double mutant $\Delta 131-159+424-495$, respectively.

A combination of linker mutagenesis and PCR was used to generate $\Delta 427-\mathrm{H}-490$. For PCR the 5' primer included an SphI site and encoded LLTDV*. This primer in combination with T7 was able to amplify the $3^{\prime}$ end of pGEX-1.1. The resulting amplification product was then subcloned into the $\mathrm{SphI}$ site of $\mathrm{pBS}-1.1(9.4 \mathrm{Sac} / \mathrm{Sph})$, followed by resubcloning into pGEX-1.1 at the BstXI site to generate $\Delta 427-\mathrm{H}-490$.

All mutated and PCR-amplified regions were sequenced on both strands using fluorescently labeled dideoxy terminators and Taq polymcrasc (Applied Biosystems) in a PCR-based sequencing protocol. The resulting sequences were analyzed by the Molecular Pharmacology Core using an $\mathrm{ABI}$ sequenator.

Oocyte expression. Plasmid DNAs were linearized with EcoRI for in vitro transcription of capped mRNAs (mCAP kit, Stratagene) using SP6 RNA polymerase. Mutant $\triangle 480-495$ mRNA was obtained by digesting pGEXKv1.1 DNA with PvuII instead of EcoRI to linearize and truncate the template prior to transcription. Adult female Xenopus laevis were anesthetized by immersion in ice water for one-half hour, followed by surgical removal of two to four ovarian lobes. Pieces of ovary were washed in a calcium-free solution (OR2) containing $82.5 \mathrm{~mm} \mathrm{NaCl}, 2$ $\mathrm{mm} \mathrm{KCl}, 1 \mathrm{mM} \mathrm{MgCl}_{2}$, and $5 \mathrm{~mm}$ HEPES (pH 7.65). Single oocytes free from follicular cells and connective tissue were obtained by treatment with $1 \mathrm{mg} / \mathrm{ml}$ collagenase (type A, Boehringer Mannheim) in OR2 at room temperature $\left(22^{\circ} \mathrm{C}\right)$ for $3 \mathrm{hr}$. Healthy oocytes at maturation stages $\mathrm{V}$ and VI were selected and transferred to a modified Barth's solution (MBS) containing $88 \mathrm{~mm} \mathrm{NaCl}, 1 \mathrm{~mm} \mathrm{KCl}, 0.82 \mathrm{mM} \mathrm{MgSO}_{4}, 0.33 \mathrm{~mm}$ $\mathrm{Ca}\left(\mathrm{NO}_{3}\right)_{2}, 0.41 \mathrm{~mm} \mathrm{CaCl}_{2}, 2.4 \mathrm{~mm} \mathrm{NaHCO}, 0.5 \mathrm{~mm}$ theophylline, 2.5 $\mathrm{mm}$ Na pyruvate, $0.1 \mathrm{mg} / \mathrm{ml}$ gentamicin, $0.01 \mathrm{mg} / \mathrm{ml}$ penicillin, 0.01 $\mathrm{mg} / \mathrm{ml}$ streptomycin, and $10 \mathrm{~mm}$ HEPES (pH 7.4). Following $24 \mathrm{hr}$ of incubation at $18^{\circ} \mathrm{C}$, the oocytes were injected with $50 \mathrm{nl}$ of $3-1000 \mathrm{pg} /$ $\mathrm{nl}$ cRNA using a Drummond microinjector. Oocytes were maintained in MBS at $18^{\circ} \mathrm{C}$ and tested for current expression 2-6 d after injection.

Electrophysiology and data analysis. For whole-cell current measurements, a two-electrode voltage clamp (TEC01, NPI clcctronics) was used. Both the voltage recording and current electrode were filled with $3 \mathrm{M} \mathrm{KCl}$ and had resistances of $0.5-2.0 \mathrm{M} \Omega$. The oocytes were placed in an $0.5 \mathrm{mll}$ chamber and perfused continuously at $5 \mathrm{ml} / \mathrm{min}$ with frog Ringer's solution (FRS) consisting of $115 \mathrm{~mm} \mathrm{NaCl}, 2.5 \mathrm{~mm} \mathrm{KCl}, 1.8$ $\mathrm{mM} \mathrm{CaCl}_{2}$, and $10 \mathrm{~mm} \mathrm{HEPES} \mathrm{(pH} \mathrm{7.2).} \mathrm{Transient} \mathrm{capacitive} \mathrm{and} \mathrm{linear}$ leakage currents were subtracted on line by the $P / 4$ procedure (Armstrong and Bezanilla, 1974) built into the data acquisition software (Instrutech ACQUIRE program). The currents were filtered at $1 \mathrm{kHz}$ and sampled at $2 \mathrm{kHz}$. The oocyte membrane was clamped at $-70 \mathrm{mV}$ and membrane currents were elicited by 250 or $1000 \mathrm{msec}$ command voltages from -70 to $50 \mathrm{mV}$ in $10 \mathrm{mV}$ increments. The time course of current inactivation during $1 \mathrm{sec}$ voltage pulses was fit by the method of least squares with a single exponential function, and time constants of inactivation were derived from these functions using an exponential curve-fitting program. The adequacy of curve fits to single exponential functions was determined by eye, with complete superposition of the fitting function and the data required. For the fitting of drug-binding isotherms to concentration-inhibition data, the adequacy of the fit was statistically evaluated with the $\chi^{2}$ goodness-of-fit test with a significance level set at $p=0.05$. All values are expressed as mean \pm SEM.

The "I" fraction of dendrotoxin (DTX-I) was purified from crude snake venom by a modification of the method of Benishin et al. (1988) and diluted in FRS to obtain the final concentrations of DTX-I with which the oocyte was perfused. To obtain concentration-inhibition data for DTX-I, a current-voltage $(I-V)$ relation was obtained from a given oocyte in FRS, and 5 min following perfusion of DTX-I another $I-V$ was sampled. This procedure was repeated for an ascending series of DTX-I concentrations. We have determined that, at the solution flow rate used, $5 \mathrm{~min}$ is an adequate time interval to obtain "steady state" current measurements in DTX-I. The peak potassium current at $50 \mathrm{mV}$ was measured in the presence of each DTX-I concentration and normalized to the current obtained in control FRS at the same voltage.

To determine the expression ratios for $\mathrm{mKvl} .1$ and $\mathrm{mKv} .3$ in the coexpression experiments, we injected the same concentrations of cRNA for $\mathrm{mKv} 1.1$ and $\mathrm{mKv} 1.3$, each alone, as were coinjected into cells from the same batch, and then determined the average peak current from at least 10 cells in each group. We could not simply coinject fixed ratios of concentrations of cRNA since, for a given concentration of cRNA $\mathrm{mKv} 1.1$ expressed current to a greater degree than $\mathrm{mKv} 1.3$. We chose not to transcribe cDNA mixtures (Kavanaugh et al., 1992) because of the differences in translation initiation sequences for $\mathrm{pGEX}-1.1$ versus pGEX-1.3. These differences may cause differential translational efficiency, thereby yielding inaccurate estimates of expression ratios based on CRNA or CDNA concentrations.

\section{Results}

\section{$m K v 1.1$ and $m K v 1.3$ form heteromultimers}

When cRNA encoding $\mathrm{mKv} 1.1$ was injected alone into Xenopus oocytes, $\mathrm{K}^{+}$currents that activated between -40 and $-50 \mathrm{mV}$ and inactivated slowly were observed (Fig. $1 A$, Table 1). These currents were also sensitive to low concentrations of DTX-I (Figs. 1 $A, 2 A$ ). The concentration of half inhibition, $K_{i}$, for DTX-I was estimated to be $3 \mathrm{~nm}$ using the best fit of a standard drug-binding isotherm to the data $(N=7$; Fig. $2 A)$. In contrast, $\mathrm{K}^{+}$currents observed following the injection of transcript for $\mathrm{mKv} 1.3$ activated between -40 and $-30 \mathrm{mV}$ and inactivated more rapidly than mKvl.1 (Fig. $1 B$, Table 1). Furthermore, $\mathrm{mKv} 1.3$ currents were virtually insensitive to DTX-I (Figs. $1 B$, $2 A$; Table 1). We never observed currents with these properties in uninjected oocytes $(N=8)$. 


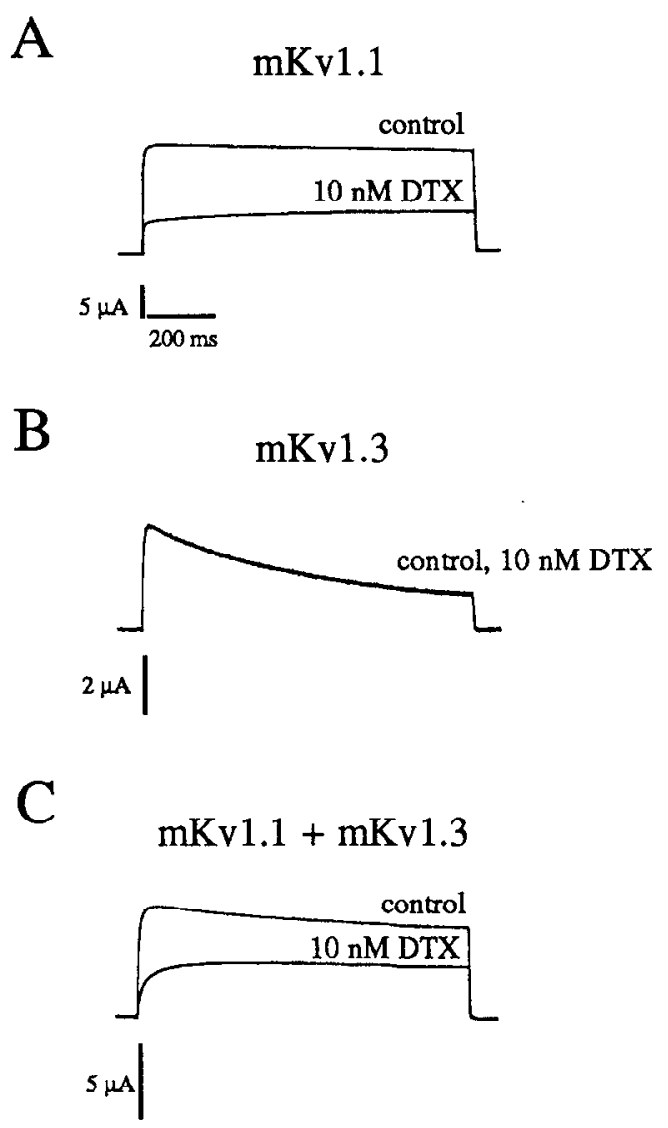

Figure 1. Membrane currents and DTX-I sensitivity for mKv1.1, $\mathrm{mKv} 1.3$, and both expressed together. $A, \mathrm{~K}^{+}$currents recorded from an oocyte injected with $\mathrm{mKv} 1.1 \mathrm{cRNA}$ in control saline, and following bath application of $10 \mathrm{~nm}$ DTX-I. $B$, The same for mKv1.3; the trace in the presence of $10 \mathrm{~nm}$ DTX-I is completely superimposed on the control trace. $C$, Currents following the coinjection of mKv1.1 and mKv1.3 in a 1:2 ratio, respectively (see Materials and Methods for ratio determination). The holding and command potentials were -70 and $50 \mathrm{mV}$, respectively. The concentrations of cRNA injected were $(A)$ $0.25 \mathrm{ng} /$ oocyte, $(B) 0.67 \mathrm{ng} /$ oocyte, and $(C) 0.08 \mathrm{ng} \mathrm{mKv1.1,0.67 \textrm {ng }}$ $\mathrm{mKv} 1.3 /$ oocyte. The time calibration in $A$ applies to all traces.

We have taken advantage of differences in DTX-I sensitivity and inactivation kinetics to provide evidence for heteromultimer formation between $\mathrm{mKv} 1.1$ and $\mathrm{mKv} 1.3$. We observed that when $\mathrm{mKv} 1.1$ and $\mathrm{mKv} 1.3$ were coexpressed in a $1: 2$ ratio, respectively, $\mathrm{K}^{+}$currents appeared with DTX-I sensitivity approaching that of mKv1.1 alone (Figs. 1C, 2A). The estimated
A
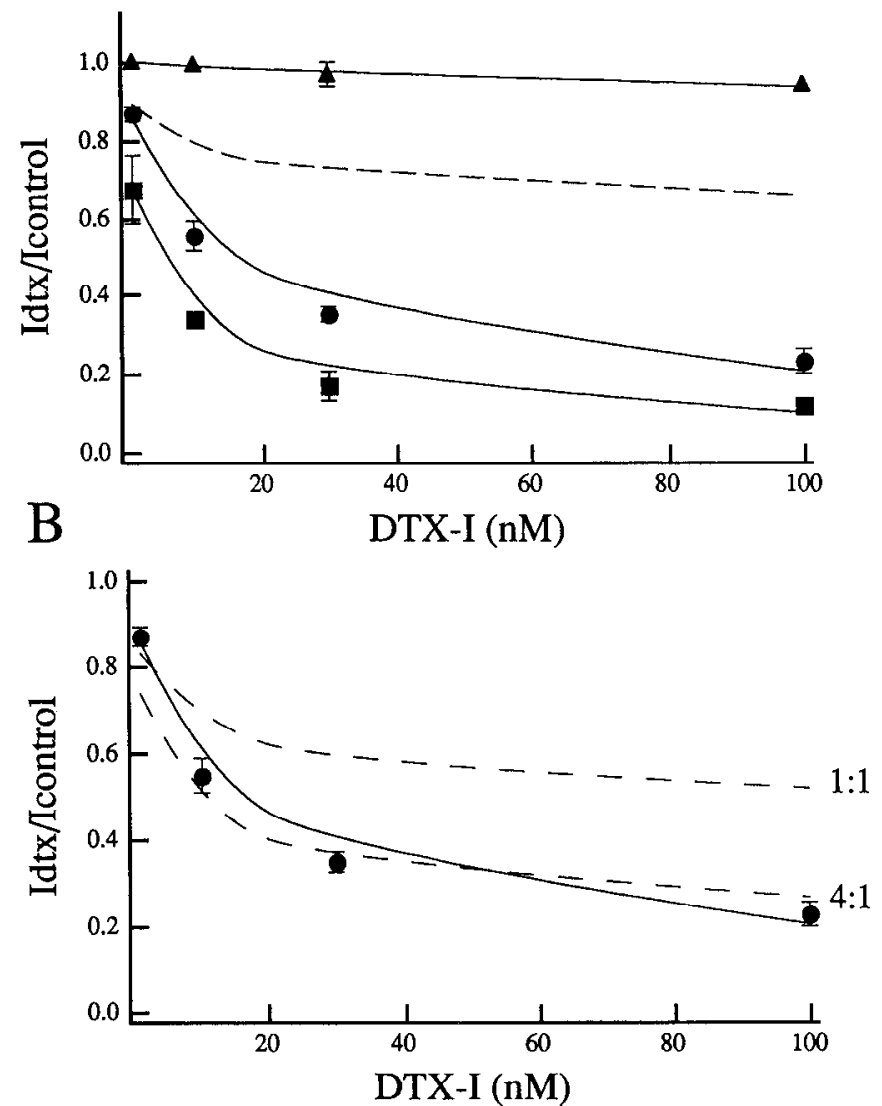

Figure 2. Deviation of DTX-I sensitivity of $\mathrm{K}^{+}$currents in coinjected oocytes from an additive model. $A$, DTX-I concentration-inhibition data for mKv1.1 (squares), mKv1.3 (triangles), and when both were coexpressed in a $1: 2$ ratio (circles). The dashed curve represents output from an additive model that assumes that $\mathrm{mKvl} 1.1$ and $\mathrm{mKv} 1.3$ express only as homomultimers (model equation given in Results). The data were taken from a total of seven oocytes for $\mathrm{mKv} 1.1,11$ for $\mathrm{mKv} 1.3$, and four for both coinjected. The solid curves represent the best-fitting drug-binding isotherm to the data points in each case. $B$, The same concentration-inhibition data for the coinjected cells shown in $A$ (circles) are compared to the results for the additive model with two possible expression ratios: $1: 1$ and $4: 1 \mathrm{mKv} 1.1$ to $\mathrm{mKv} 1.3$ (labeled dashed curves).

$K_{i}$ for the coinjection data shown in Figure 2 was $14 \mathrm{~nm}(N=$ 4). If $\mathrm{mKvl} 1$ and $\mathrm{mKv1.3}$ are expressed only as homomultimers, then an additive model consisting of DTX-I-binding isotherms for both mKv1.1 and mKv1.3 should adequately de-

Table 1. Properties of mKv1.1, mKv1.3, heteromultimers, and two C-terminal truncation mutants of mKv1.1 expressed in Xenopus oocytes

\begin{tabular}{|c|c|c|c|c|c|}
\hline & \multirow[b]{2}{*}{$\begin{array}{l}\mathrm{K}_{\mathrm{i}}(\mathrm{DTX}-\mathrm{I}) \\
(\mathrm{nM})\end{array}$} & \multirow[b]{2}{*}{$\begin{array}{l}\text { Inactivation tau } \\
\text { (msec) }\end{array}$} & \multicolumn{3}{|c|}{ Prepulse inactivation } \\
\hline & & & $\begin{array}{l}k \\
(\mathrm{mV} / e \text {-fold })\end{array}$ & $\begin{array}{l}V_{1 / 2} \\
(\mathrm{mV})\end{array}$ & $F_{\text {noninact }}$ \\
\hline $\mathrm{mK} \times 1.3$ & $4533(11)$ & $694 \pm 61$ & $3.5 \pm 0.1$ & $-26 \pm 1.0$ & $0.26 \pm 0.02(15)$ \\
\hline $1 \mathrm{mKv} 1.1$ to $2 \mathrm{mKv} 1.3$ & $14(4)$ & $1843 \pm 264(4)$ & $4.2 \pm 0.4$ & $-24 \pm 1.9$ & $0.54 \pm 0.03(5)$ \\
\hline $\mathrm{mKv} 1.1 \Delta 480-495$ & & $3810 \pm 166(4)$ & & & \\
\hline
\end{tabular}

$K_{i}$ values for DTX-I were determined from the best-fitting binding isotherms to averaged concentration-inhibition data. All inactivation time constants were obtained at $20 \mathrm{mV}$. Prepulse inactivation was assessed by applying a 5 sec prepulse to voltages between -90 and $10 \mathrm{mV}$ in $10 \mathrm{mV}$ increments followed by a $250 \mathrm{msec}$ test pulse to $20 \mathrm{mV}$ from a holding potential of $-70 \mathrm{mV}$. The prepulse inactivation parameters, $k$ (slope factor) and $V_{1 \mathrm{~h}}$ (voltage at which half of the completely inactivating fraction of the total current inactivates), were determined from the best-fitting Boltzmann functions, and $F_{\text {inoninar }}$ refers to the fraction of the total $\mathrm{K}^{+}$current that did not inactivate using this protocol. The total number of oocytes for each parameter, or parameters in the case of prepulse inactivation, is given in parentheses. 


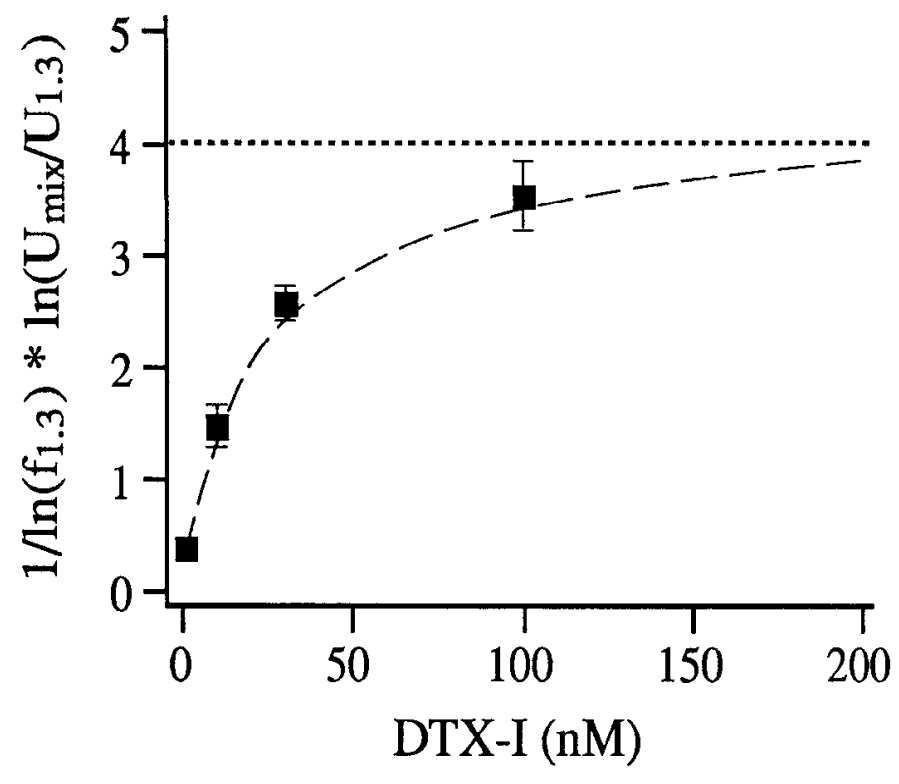

Figure 3. DTX-I data predict a channel subunit stoichiometry of 4. The analytical approach of MacKinnon (1991) was applied to the DTX-I data shown in Figure 2. The ordinate variable is based on the left side of Equation 5 from Mackinnon (1991), with $f_{1.3}=0.67(2 \mathrm{mKv} 1.3$ to $1 \mathrm{mKv} l .1$ expression ratio), and $U_{\text {mix }}$ and $U_{1.3}$ corresponding to the unblocked fraction of current for the coinjected cells $(N=4)$ and cells injected with transcript for mKv1.3 alone $(N=11)$, respectively. The curve is independent of the data and derived from the right half of Equation 5 assuming a subunit stoichiometry of 4 , which provided a better fit to the data than the three or five subunit cases (not shown). Both the data and theoretical curve converge on a value of 4 . Higher concentrations of DTX-I were not used since they usually killed the oocyte.

scribe the data from the coinjected oocytes. We used the following equation to implement the additive model:

$$
\begin{aligned}
U- & F_{1.1}\left(1-\left(X^{n} / X^{n}+K_{i 1.1}{ }^{n}\right)\right) \\
& +\left(1-F_{1.1}\right)\left(1-\left(X^{n} / X^{n}+K_{i 1.3}^{n}\right)\right)
\end{aligned}
$$

where $U$ is the unblocked fraction of $\mathrm{K}^{+}$current, $F_{1.1}$ is the fractional expression of $\mathrm{mKv} 1.1\left(F_{1.1}=0.33\right.$ for the data shown in Fig. 2), $X$ is the DTX-I concentration, $n$ is the Hill coefficient, and $K_{i 1.1}$ and $K_{i 1.3}$ are the concentrations of half-inhibition for $\mathrm{mKv} 1.1$ and $\mathrm{mKVl} .3$ by DIX-I, respectively (Table 1). The values for the Hill coefficients used, derived from concentrationinhibition data for oocytes injected with $\mathrm{mKv} 1.1$ or $\mathrm{mKv} 1.3$ alone, were 0.63 and 0.72 , respectively. The model outputs, assuming a 1:2 expression ratio for $\mathrm{mKvl} .1$ and $\mathrm{mKvl} .3$, for four concentrations of DTX-I are given in Figure $2 \mathrm{~A}$. It is clear that the data deviated significantly from the additive model, in that they displayed much greater DTX-I sensitivity than the model would predict. This approach assumes that we have accurately determined the expression ratio for $m \mathrm{Kv} 1.1$ to $\mathrm{mKv} 1.3$. We used an analytical approach devised by MacKinnon (1991) and our DTX-I data to obtain an estimate for the $\mathrm{K}^{+}$channel subunit stoichiometry (see below). Since the results obtained with that approach are very sensitive to the accuracy of the expression ratio estimate for the two types of subunits, it suggests that our method for determining this was appropriate. To determine if any output from this additive model could yield results similar to the observed data, we altered the expression ratio (the weighting of each binding isotherm, $F_{1,1}$ in the equation above) to yield the model result best fitting the data (Fig. $2 B$ ). The best-fitting additive model corresponds to an expression ratio of $4 \mathrm{mKvl} .1$ to $1 \mathrm{mKv} 1.3$. Although this is a statistically adequate fit $(p>0.05)$, it overestimates the DTX-I block at the two lowest concentrations. More importantly, this expression ratio greatly deviates from the measured ratio. The peak currents for $\mathrm{mKvl} .1$ and $\mathrm{mKvl} .3 \mathrm{cRNA}$, when each are injected alone in oocytes from the same batch, were $1.41 \pm 0.17 \mu \mathrm{A}(N=8)$ for $\mathrm{mKvl} .1$ and $2.89 \pm 0.28 \mu \mathrm{A}(N=13)$ for $\mathrm{mKv1}$.3. Hence for the additive model to hold, $\mathrm{mKv} 1.1$ would have had to be expressed to a much higher degree (4:1) in the coinjected oocytes, relative to $\mathrm{mKv} 1.3$, than was observed for the separately injected oocytes $(1: 2)$. Similar results were obtained in nine other coinjected oocytes from two separate batches.

Since the properly weighted additive model did not adequately describe the data, the most likely alternative hypothesis is that heteromultimeric $\mathrm{K}^{+}$channels, consisting of both $\mathrm{mKvl} .1$ and $\mathrm{mKv1.3}$ subunits, can form and have DTX-I sensitivity intermediate between $\mathrm{mKv} 1.1$ and $\mathrm{mKv} 1.3$. Furthermore, the results suggest that the DTX-I sensitivity of most if not all types of heteromultimers formed are much closer to that of $\mathrm{mKv} 1.1$ than to $\mathrm{mKv} 1.3$.

Differences in the kinetics of inactivation between $\mathrm{mKv} .1$ and $\mathrm{mKv} 1.3$ provided an independent variable for analyzing the formation of heteromultimers. For the four coinjected oocytes previously mentioned, the observed time constant of inactivation was $1843 \pm 264 \mathrm{msec}$ (measured at $20 \mathrm{mV}$ ), intermediate between $\mathrm{mKv1} 1$ and $\mathrm{mKv1} 1.3$, but much closer to that of mKv1.1 (Table 1). The sum of two exponential terms, each describing the inactivation kinetics of $\mathrm{mKv} 1.1$ and $\mathrm{mKv} 1.3$ and weighted by their respective expression ratios, was fitted to the currents elicited by $1 \mathrm{sec}$ command pulses to $20 \mathrm{mV}$ for each of these coinjected oocytes. In each case, the inactivation time course predicted by the additive model was considerably faster than the observed data, and therefore could not provide an adequate fit to the data (data not shown). As with the DTX-I data, the additive model could provide adequate fits to the observed inactivation time courses only if the expression ratios for $\mathrm{mKv1.1}$ and $\mathrm{mKvl} .3$ in the coinjected oocytes were assumed to be greatly weighted toward much higher expression of $\mathrm{mKv1.1}$ than that observed in separately injected oocytes.

\section{Subunit stoichiometry}

Using a novel analytical approach, and a point mutation in ShB $\mathrm{K}^{+}$channel subunits that renders them virtually insensitive to charybdotoxin, MacKinnon (1991) was able to estimate the subunit stoichiometry for this $\mathrm{K}^{+}$channel in Xenopus oocytes. We applied the assumptions and equations of that approach to the DTX-I data shown in Figure $2 A$, since they are analogous to the charybdotoxin data. The results are shown in Figure 3. The averaged data from the four oocytes appear to converge on a value of 4 as DTX-I concentration is increased. The theoretical curve, which assumes a subunit stoichiometry of 4 , provided a very good fit to the data, while the curves for the three or five subunit cases did not (data not shown). The data provide further support for the hypothesis that voltage-gated $\mathrm{K}^{+}$channels are tetramers.

\section{Expression of $N$ - and C-terminal deletion mutants of $m K v 1.1$}

A total of $11 \mathrm{~N}$-terminal, three C-terminal, and one combined $\mathrm{N}$ - and C-terminal deletion mutants of $\mathrm{mKv}$.1 were tested in 


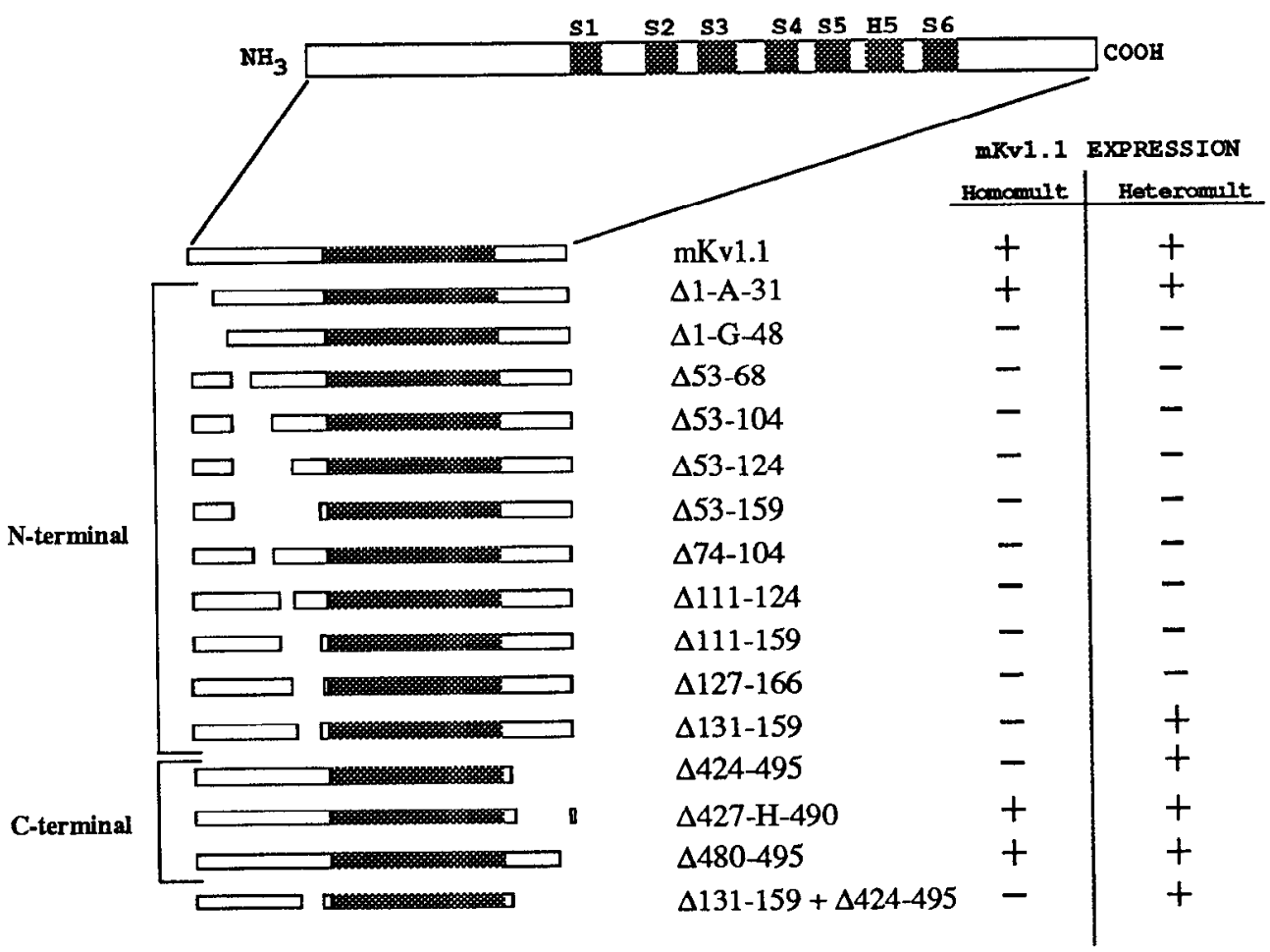

Figure 4. Deletion mutants and summary of results. A schematic of the coding region of $\mathrm{mKvl} .1$ is shown at the top, with putative membrane-spanning domains (S1-S6) and pore region (H5) shaded. The $\mathrm{N}$ - and C-terminal domains, and extracellular and cytoplasmic loops joining membrane-spanning regions are not shaded. Schematic diagrams of 15 deletion mutants tested in the study, with the corresponding amino acids deleted, are shown below. Amino acids are numbered from the beginning of the coding region. The single letters inserted for three of the mutants correspond to amino acids that were inserted to restore the restriction sites and keep the nucleotide sequence of the original cDNA construct in frame (see Materials and Methods). The $G$ corresponds to glycine, $A$ to alanine, and $H$ to histidine. A summary of the results is shown on the right, with "homomult" denoting expression as a homomultimer, that is, injected alone, and "heteromult" corresponding to expression as a heteromultimer when coinjected with wild-type $\mathrm{mKv} 1.3$. this study. Figure 4 depicts all of these mutants with their relative positions and sizes in schematic form, as well as the amino acid residues that were deleted from the $\mathrm{N}$-terminus, $\mathrm{C}$-terminus, or both. The cRNA transcribed from the mutant cDNAs was always injected undiluted to optimize detection of expression. The amount of cRNA injected, estimated from optical density readings, was $25-50 \mathrm{ng} /$ oocyte. In every case, transcript size and quality were confirmed by formaldehyde denaturing gel analysis.

To determine possible structural requirements for assembly and expression of $\mathrm{mKvl} .1$ as a homomultimer or heteromultimer with mKv1.3, we injected cRNA encoding the mutants alone or with a fixed concentration of cRNA encoding wildtype $\mathrm{mKv} 1.3(0.17 \mathrm{ng} /$ oocyte $)$. The same concentration of mKv1.3 cRNA alone was injected in oocytes from each batch as a control to assess expression of $m \mathrm{Kv} 1.3$. The average $\mathrm{K}^{+}$ current in oocytes injected with $0.17 \mathrm{ng}$ of $\mathrm{mKv} 1.3 \mathrm{cRNA}$ was $1.50 \pm 0.24 \mu \mathrm{A}$ measured at $50 \mathrm{mV}(N=21)$. To determine whether $\mathrm{mKvl} .3$ expression was constant over the several months of the study, we split these data into two roughly equal groups corresponding to the first and second half of the study. The average $\mathrm{K}^{+}$current for the first half was $1.56 \pm 0.30 \mu \mathrm{A}$ $(N=10)$ and for the second half was $1.45 \pm 0.39 \mu \mathrm{A}(N=11)$. Therefore, neither the stability of the transcript nor the ability of the oocytes to express $\mathrm{K}^{+}$current following injection of a fixed concentration of cRNA encoding mKv1.3 varied significantly over the course of the study.

The expression results obtained when cRNA encoding each deletion mutant was injected alone to test for homomultimer formation are summarized in Figure 4. Each data point is based on recordings from 4-12 oocytes for each mutation. Of the N-terminal mutants, only the $\Delta 1-\mathrm{A}-31$ mutant, in which the first 31 amino acid residues were deleted, yielded measurable $\mathrm{K}^{+}$currents. All others displayed currents that were indistinguishable from those observed in uninjected oocytes (data not shown). For the C-terminal mutants, the $\Delta 480-495$ and $\Delta 427$ $\mathrm{H}-490$ each yielded $\mathrm{K}^{+}$currents, while the $\Delta 424-495$ mutant did not. The $\mathrm{N}$ - and $\mathrm{C}$-terminal double mutant, $\Delta 131-159+$ $\Delta 424-495$, also did not express $K^{+}$current, as would be predicted from the results of each separate mutation.

The results of the experiments in which cRNA encoding deletion mutants was coinjected with wild-type mKvl.3 to test for heteromultimer formation are shown in Figure 5 for seven of the $11 \mathrm{~N}$-terminal and all of the C-terminal and double mutants. The averaged data are based on measurements from 312 oocytes for each mutation. Figure $5 A$ depicts the percentage block of a concentration of DTX-I (10 nM) that distinguishes between mKv1.1 and mKv1.3 (upper two bars; see also Fig. $1 A, B)$. The third bar corresponds to the DTX-I sensitivity of $\mathrm{K}^{+}$currents from oocytes coinjected in a $1: 2$ ratio of $\mathrm{mKv} 1.1$ and $\mathrm{mKv} 1.3$, respectively. The $\mathrm{N}$-terminal mutants are grouped in a linear sequence down from the start of the coding region to within two residues of the first putative membrane-spanning domain. For this group, the $\Delta 1-A-31$ (first) and $\Delta 131-159$ (last) mutants were able to express as heteromultimers, as determined from the intermediate DTX-I sensitivity of the resulting $\mathrm{K}^{+}$ currents (Fig. 5A). The remaining five mutants, $\Delta \mathrm{l}-\mathrm{G}-48$ to $\Delta 127-166$ (central), displayed currents with DTX-I sensitivity similar to $\mathrm{mKv} 1.3$ alone. As these mutants neither added mKv1.1-like increased DTX-I sensitivity nor significantly reduced expression of $\mathrm{mKv} 1.3$, as determined by comparing $\mathrm{K}^{+}$ current amplitude in the coinjected cells with cells injected with mKv1.3 cRNA alone (data not shown), we conclude that they were unable to assemble and express as functional heteromultimers. The remaining four N-terminal mutants (Fig. 4), which are not shown in Figure $5 A$, each encompass larger deletions within the domain spanned by the five nonexpressing mutants, and also did not express as heteromultimers. All three C-terminal mutants, which together span from 13 amino acid residues from the sixth putative membrane-spanning domain to the 
A
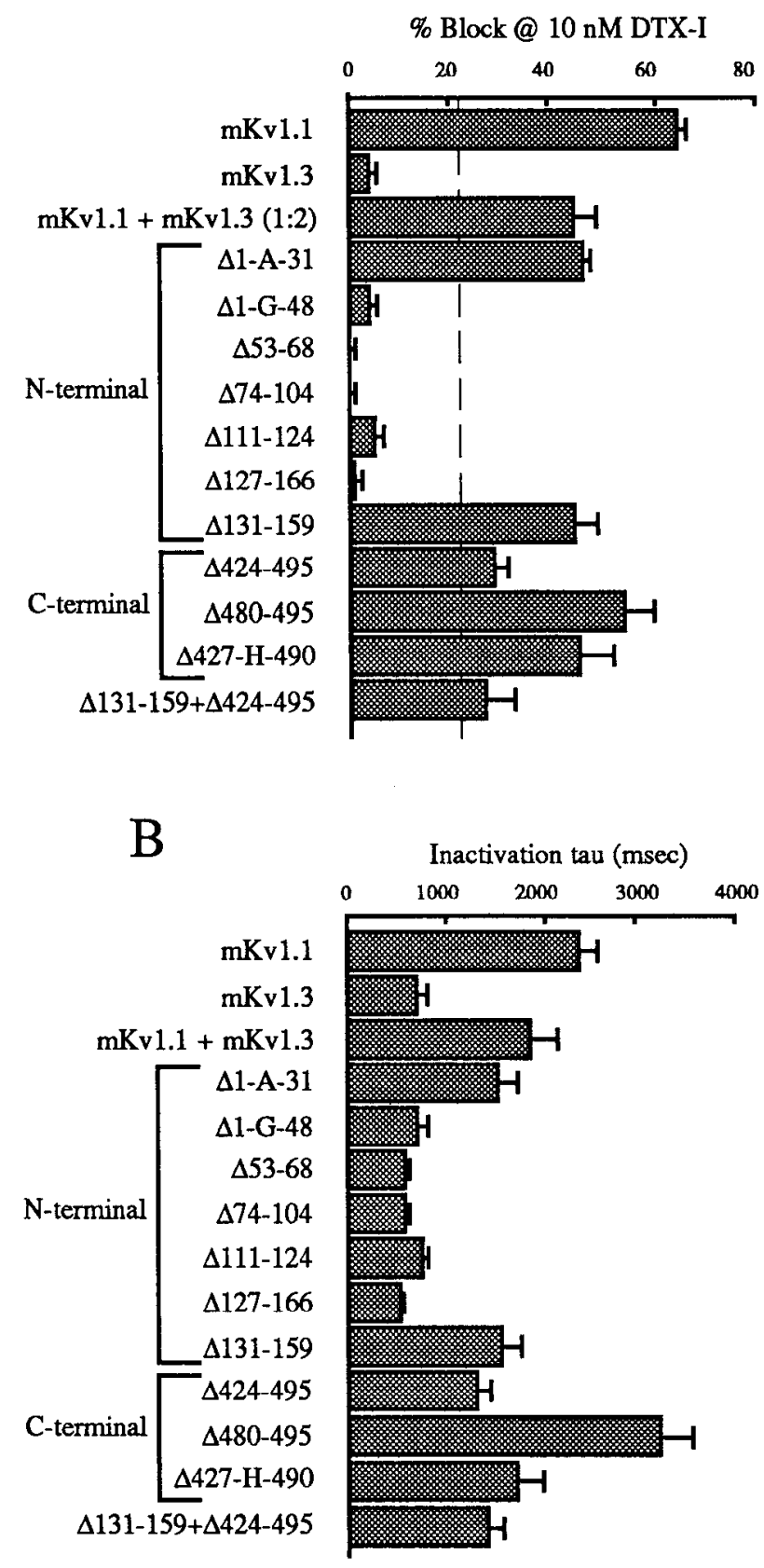

Figure 5. DTX-I and inactivation time constant data summary for the $\mathrm{mKv} 1.1$ deletion mutants coinjected with $\mathrm{mKv} 1.3 . A$, The average block (\%) of $\mathrm{K}^{+}$current by $10 \mathrm{nM}$ DTX-I is shown for wild-type mKv1.1, mKv1.3, and when transcripts encoding both are coinjected in a $1: 2$ ratio, respectively. The dashed line corresponds to the predicted block for an additive model assuming a 1:2 expression ratio for $\mathrm{mKv} 1.1$ and $\mathrm{mKv} 1.3$, respectively. All of the data following these three groups are from oocytes coinjected with cRNA encoding deletion mutants and wild-type mKv1.3. The N-terminal deletion mutants are grouped together and sequentially span from the start site to within two amino acid residues of the first pulative membrane-spanning domain. The three C-terminal mutants are grouped below, with a combined $\mathrm{N}$ - and C-terminal mutant shown last. The concentrations of deletion mutant cRNA injected were variable, but were always undiluted (25-50 ng/ oocyte), while the concentration of mKv1.3 cRNA was always $0.17 \mathrm{ng} /$ oocyte. $B$, The average inactivation time constants, in msec (see Materials and Methods), sampled in FRS, are shown for the same data set depicted in $A$. end of the coding region, wcre ablc to express as heteromultimers (Fig. 5A). The double mutant $\Delta 131-159+\Delta 424-495$ was also able to associate with $\mathrm{mKv} 1.3$, as did each mutation separately.

This pattern of results was perfectly corroborated by the inactivation time constant data (Fig. 5B). Again, inactivation time constants for wild-type $\mathrm{mKv1.1,} \mathrm{mKv} 1.3$, and following coinjection in a $1: 2$ ratio, respectively, are given by the first three bars. The $\Delta 1-A-31$ and $\Delta 131-159 \mathrm{~N}$-terminal mutants displayed intermediate inactivation time constants characteristic

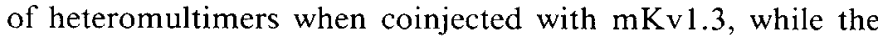
other five mutants did not. For the C-terminal mutants, the inactivation time constants for $\Delta 424-495$ and $\Delta 427-H-490$ coinjected with $\mathrm{mKv} 1.3$ were similar to those displayed by heteromultimers. Similarly, the double mutant $\Delta 131-159+\Delta 424$ 495, when coexpressed with $\mathrm{mKv} 1.3$, yielded $\mathrm{K}^{+}$currents that inactivated with an average time constant characteristic of heteromultimers of each separate mutation (Fig. $5 B$ ). The high correlation between the DTX-I data and the inactivation time constant data make it unlikely that the pattern of results observed with DTX-I was due to altered DTX-I sensitivity in the mKv1.1 mutants. However, the $\Delta 480-495$ mutant coinjected with $\mathrm{mKv} 1.3$ yielded unusually large inactivation time constants $(3128 \pm 288 \mathrm{msec}$ at $20 \mathrm{mV}, N=5)$, larger even than wild-type $\mathrm{mKv} 1.1$. Furthermore, the average inactivation time constant of this mutant, expressed as a homomultimer, was $3810+166 \mathrm{msec}(N=4)$. This is almost twice as large as the inactivation time constant for $\mathrm{mKv} 1.1$ (Table 1), and therefore represents an altered phenotype resulting from this mutation. That the inactivation time constant for this mutant coinjected with $\mathrm{mKv} 1.3$ was somewhat smaller than the mutant expressed alone suggests that it was able to form heteromultimeric channels with mKvl.3. A summary of the expression results for all of the deletion mutants coinjected with $\mathrm{mKvl} .3$ is given in Figure 4.

\section{Discussion}

As a first step to evaluating the possible role of the $\mathrm{N}$ - and C-terminal domains in the ability of $\mathrm{mKv} .1$ to express functional $\mathrm{K}^{+}$channels, we constructed a series of interstitial and truncation deletion mutants that together spanned virtually all of each domain. After establishing that wild-type mKv1.1 and mKv1.3 were able to form heteromultimers with a probable subunit stoichiometry of 4 , we injected cRNA encoding each mutant alone or in combination with wild-type $\mathrm{mKv} 1.3$ to determine the ability to form functional homomultimers or heteromultimers in Xenopus oocytes. We found that all of the C-terminal mutants tested could express functional channels as either a homomultimer or heteromultimer or both. In contrast, only two of the $11 \mathrm{~N}$-terminal mutants could do so.

In contrast to the dominance of fast, $\mathrm{N}$-terminal-mediated inactivation observed when rapidly inactivating Shaker $A$ and slowly inactivating mutant Shaker B subunits are coexpressed (Isacoff et al., 1990), we observed that mKvl.1 provides the dominant phenotype for slow inactivation kinetics. This was also the case for DTX-I sensitivity, since both toxin sensitivities and the inactivation time constants of currents from coinjected oocytes were much closer to $\mathrm{mKvl} .1$ than to $\mathrm{mKv} 1.3$. In this regard, it is interesting that differences in both DTX-I sensitivity and inactivation kinetics between the rat homologs of $\mathrm{mKvl} 1.1$ and $\mathrm{mKv} 1.3$ have been attributed, at least in part, to the identity of one amino acid residue between S5 and S6, near the putative mouth of the channel pore. A histidine residue at position 401 


\begin{tabular}{|c|c|c|c|}
\hline Name & C-term. sequence & Size & Species \\
\hline ShA & NNAMAVSIETDV* & 616 & Drosophila \\
\hline $\operatorname{Sh} B$ & NNALAVSIETDV* & 656 & Drosophila \\
\hline AK01 & NPGSDYGLETDV* & 515 & Aplysia \\
\hline XSh2 & NYVNITKMLTDV* & 499 & Xenopus \\
\hline 1.1 & NCVNKSKLLTDV* & 495 & Mouse \\
\hline 1.2 & NYVNITKMLTDV* & 499 & Mouse \\
\hline 1.3 & SCVNIKKIFTDV* & 530 & Mouse \\
\hline 1.4 & NCSNAKAVETDV* & 655 & Rat \\
\hline 1.5 & ALCLDTSRETDL * & 602 & Rat \\
\hline 1.6 & RAYAEKRMLTEV * & 529 & Mouse \\
\hline
\end{tabular}

results in less sensitivity to DTX-I and faster inactivation than when tyrosine resides at this position (Busch et al., 1991; Hurst et al., 1991).

A possible molecular interpretation of dominant phenotypes is suggested by considering the subunit composition of the resulting channels in a mixing experiment such as this. Let us assume that subunits assemble randomly, and therefore binomial statistics accurately describe the assembly of mKv1.1 and $\mathrm{mKv} 1.3$ subunits into channels composed of four subunits with all possible subunit compositions ( $1 \mathrm{mKvl} .1$ to $3 \mathrm{mKv} 1.3,2$ $\mathrm{mKv} 1.1$ to $2 \mathrm{mKvl} 3$, etc). With the $1 \mathrm{mKv} 1.1$ to $2 \mathrm{mKv} 1.3$ expression ratio displayed in this experiment, we would predict that $80 \%$ of the channels have at least one mKv1.1 subunit, but that only about $40 \%$ have two or more $\mathrm{mKv} 1.1$ subunits. Therefore, in order for a particular mKv 1.1 property to be dominant as measured by whole-cell recording, it must be the case that a channel need have only one mKvl.1 subunit to express the mKvl.1 phenotype. Analogous to studies using charybdotoxin (MacKinnon, 1991), it may be that one DTX-I-sensitive subunit provides a sufficient binding site to confer nearly full DTX-I sensitivity on a channel complex. In the case of slow inactivation kinetics, it is possible that a channel's inactivation properties are largely determined by the kinetics contributed by its "slowest" subunit.

\section{Synthesis and stability of mutant subunits}

When cRNA encoding each of the deletion mutants was coinjected with transcript encoding mKv1.3 (heteromultimer expression), the pattern of results was not identical to what was observed with each deletion mutant injected alone (homomultimer expression, Fig. 4). That is, one N-terminal ( $\Delta 131-159)$ and one $C$-terminal $(\Delta 424-495)$ deletion mutant could not express as homomultimers, but were able to express as heteromultimers with mKv1.3 (Fig. 5). These data suggest that protein is made from these deletion mutants and is available to assemble with intact mKv1.3 subunits. In contrast, several N-terminal deletions showed no effect on the expression of $\mathrm{mKv} 1.3$ upon coinjection. The results of Li et al. (1992) suggest that mutants lacking these $\mathrm{N}$-terminal regions would not bind biochemically to intact channel subunits. Thus, our inability to detect $\mathrm{mKv} 1.1$ like currents from these deletion mutants is likely to result from their failure to assemble either with mKv1.3 (heteromultimers) or with each other (mutant homomultimers). Further support for this conclusion comes from our observation that these mutants did not block or reduce expression of $\mathrm{mKv} 1.3$ in a dominant negative fashion, as would be expected had the $\mathrm{N}$-terminal region alone been expressed (Isacoff et al., 1990).

Comparing all of our deletion constructs, our results indicate

\section{Reference}

\author{
Tempel et al., 1987 \\ in Drewe et al., 1992 \\ in Drewe et al., 1992 \\ in Drewe et al., 1992 \\ Tempel et al., 1988 \\ Chandy et al., 1990 \\ Chandy et al., 1990 \\ Stühmer et al., 1989 \\ Swanson et al., 1990 \\ Migeon et al., 1992
}

Figure 6. Distal C-terminal amino acid sequence lineup for several Shaker subfamily members. The amino acid sequence of the distal C-termini of several members of the Shaker subfamily from a variety of species are given (standard single letter code), as well as the predicted size of the polypeptide (tota amino acid residues). Note the strong sequence conservation of the last three residues (identical residues in bold type). that the location of the deletion was more important than its size. For example, both the $\Delta 53-124$ and $\Delta 424-495$ mutants each deleted 71 amino acid residues in the $\mathrm{N}$ - and $\mathrm{C}$-termini, respectively. However, the $\mathrm{C}$-terminal mutant was able to express as heteromultimers, whereas the $\mathrm{N}$-terminal mutant did not display any form of expression. The $\Delta 427-\mathrm{H}-490$ mutant consisted of a 63 amino acid deletion in the C-terminus that was able to express as both homomultimers and heteromultimers. This deletion was larger than seven of the nine N-terminal deletions that did not display any form of expression. It was therefore not the case that the probability of expression was simply related to the size of the deletion.

\section{Functional role of the C-terminus}

The importance of the distal C-terminus in Shaker-like $\mathrm{K}^{+}$ channel proteins for their stability and function is suggested by the remarkable amino acid sequence conservation displayed within this region between channel proteins from phylogenetically diverse species, such as flies, mollusks, amphibians, and mammals (Fig. 6; Drewe et al., 1992). With this conservation in mind, it is interesting to note that our data suggest the distal C-terminus (i.e., the last five amino acid residues) may contribute to $\mathrm{K}^{+}$channel stability and function. The $\Delta 424-495$ C-terminal mutant channels were able to express only as heteromultimers, whereas the $\Delta 427-\mathrm{H}-490$ mutant could express as both homomultimers and heteromultimers. Hoshi et al. (1991) had suggested the possible importance of the last five amino acid residues of the C-terminus in the expression of Shaker A and $\mathrm{B} \mathrm{K}^{+}$channels. These residues are clearly not required for channel function, since the $\Delta 480-495$ mutant was able to express as homomultimers and heteromultimers. However, the presence of residues 490-495 does restore homomultimeric function to the large C-terminal mutant $\Delta 424-495$. It is therefore possible that these residues enhance the protein stability of what would otherwise be a severely truncated protein, but that this could also be accomplished by associating with wild-type subunits (mKv1.3).

Our results also suggest that the distal C-terminus may play a role in the slow inactivation exhibited by $\mathrm{mKv} 1.1$. The $\Delta 480$ 495 mutant, expressed as a homomultimer, exhibited considerably slower inactivation than wild-type mKv1.1, whereas the time constants for the $\Delta 427-\mathrm{H}-490$ mutants, also expressed as homomultimers, were nearly identical to mKv1.1 (Table 1). This form of inactivation (time constant of 2-3 sec) is slower than other types of slow inactivation that have been identified and attributed to the presence of specific amino acid residues in other regions of Shaker or Shaker-like $\mathrm{K}^{+}$channel proteins (Busch et al., 1991; Hoshi et al., 1991). We have not yet con- 
Figure 7. N-terminal domain required for expression of $\mathrm{mKv1.1}$. The amino acid sequences of the $\mathrm{N}$-terminus for mKvl.1 and $\mathrm{mKv} 1.3$ are given (standard single-letter code), with identical residues denoted with a dash. The domain suggested by our results to be required for expression of $\mathrm{mKv} 1.1$ is shown as a bar over the $m K v 1.1$ sequence. The uncertainty in the size of this domain is denoted by crosshatchings. For comparison, the domain determined by Li et al. (1992) is also shown as a dashed line over the $m K v 1.1$ sequence.

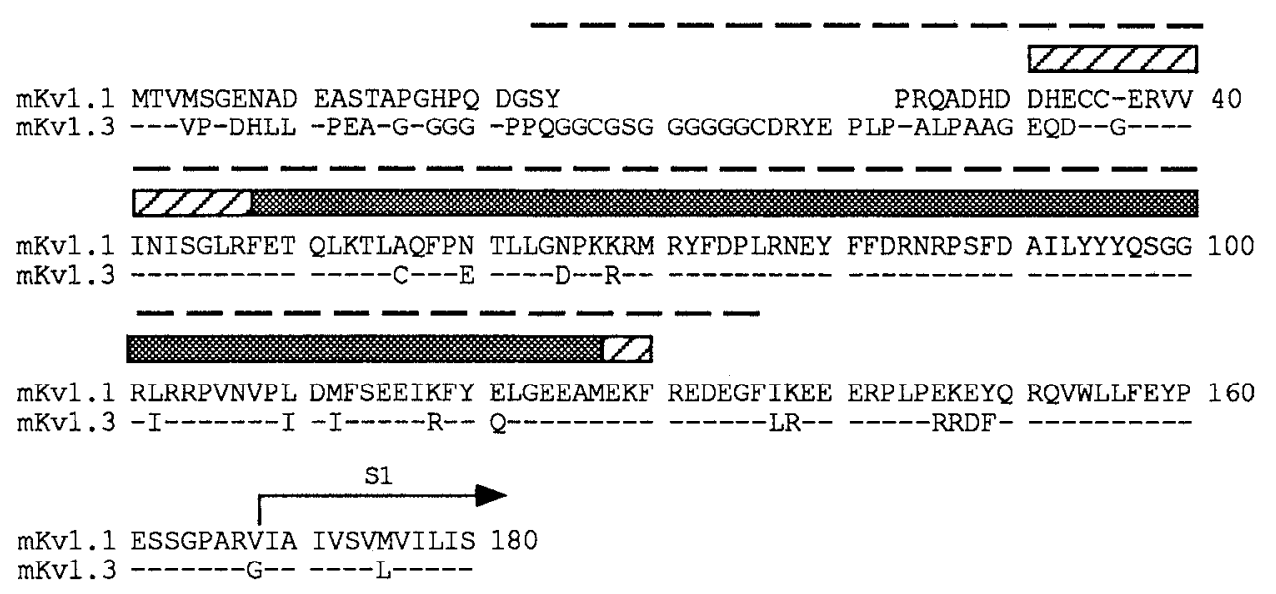

mKV1. 1 MTVMSGENAD EASTAPGHPO DGSY

PROADHD DHECC-ERVN 40

mKv1.3 ---VP-DHLL -PEA-G-GGG -PPQGGCGSG GGGGGCDRYE PLP-ALPAAG EQD--G----

mKV1.1 INISGLRFET QLKTLAQFPN TLLGNPKKRM RYFDPLRNEY FFDRNRPSFD AILYYYQSGG 100

mKvl. 3 -

mKV1. I RLRKYVNVPL DMF'SEEIKF'Y ELGE'L'AME'KH' RE'DE'GH'IKE'E' E'RPLPE'KEYY RQVWLLFEYP 160

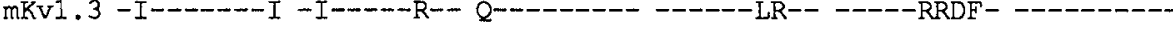

structed and tested a $\Delta 491-495$ mutant mKv1.1, and therefore do not know that this form of slow inactivation is specifically mediated by the distal five C-terminal residues. Nevertheless, it is intriguing that several kinetically distinct mechanisms of $\mathrm{K}^{+}$channel inactivation may be mediated by distinct regions of the channel protein, and involve conformation-dependent interactions between predicted transmembrane and hydrophilic regions (Timpe et al., 1988; Iverson and Rudy, 1990; Busch et al., 1991 ; Hoshi et al., 1991; Stocker et al., 1991).

\section{Functional expression requires a specific $N$-terminal domain}

The pattern of results obtained for the $\mathrm{N}$-terminal deletions (Fig. 5) suggests a more specific conclusion regarding a functional role for the highly conserved central domain of the N-terminus of these Shaker-like subunit proteins (Fig. 7). The $\Delta 1$-A-31 mutant, in which the first 31 amino acids were deleted, was able to express as both homomultimers and heteromultimers. The $\Delta 131-$ 159 mutant expressed only as a heteromultimer. The five relatively small interstitial deletion mutants that span from residue 48 to 127 between these two mutants did not display any form of expression, nor did any of the four mutants that encompass larger deletions within this region (Fig. 4). These results alone do not enable us to conclude that mutants that did not express were defective in the ability to assemble. However, our data and the results of $\mathrm{Li}$ et al. (1992) taken together suggest that a central domain within the N-terminus, which is as small as 80 residues and as large as 99 residues, is required for assembly and functional expression of $\mathrm{mKvl} .1$ in any form (homomultimers or heteromultimers). The uncertainty in the size of this domain is related to the resolution offered by the relative sizes of the deletions used. We have delineated this domain within the N-terminus, with its size uncertainty, in Figure 7. The amino acid sequence of the $\mathrm{N}$-terminus of $\mathrm{mKv} 1.3$ is aligned with that of $\mathrm{mKvl} .1$ to illustrate the large degree of amino acid sequence identity between the two channel subunit proteins in this region. This N-terminal domain is similar to that which was identified by Li et al. (1992) for Shaker gene subfamily K' channel subunit assembly. Our results suggest, however, that this domain is somewhat shorter than the one proposed by them, as our linkermutagenesis approach enabled us to design specific interstitial deletion constructs that could more closely define the critical region. For example, $\Delta 1-\mathrm{A}-31$ was designed specifically to leave intact the beginning of the N-terminal region that is highly conserved between $\mathrm{mKv} 1.1$ and $\mathrm{mKv} 1.3$ (Fig. 7). This mutant, but not the next larger one $(\Delta 1-\mathrm{G}-48)$ which deleted 17 additional residues in this region, was able to express functional channels. The relatively small size and nonoverlapping distribution of our nine interstitial deletions provide the novel and important insight that the structural integrity of this entire region is important for functional expression of mKvl.1. Another functional test for the role of the N-terminus in subunit assembly was provided by $\mathrm{Li}$ et al. (1992), who found that heteromultimers across two $\mathrm{K}^{+}$channel subfamilies can form when the $\mathrm{N}$-terminal region in Shaker $\mathrm{B}$ is incorporated at the $\mathrm{N}$-terminus of a chimeric Shaker B-drk 1 (rKv2.1) channel.

In a study similar to ours, VanDongen et al. (1990) found that deleting the first 139 amino acid residues of the 182 residue $\mathrm{N}$-terminus of $\mathrm{KKv} 2.1$ (drk1) resulted in functional, albeit modified, $\mathrm{K}^{+}$channels in Xenopus oocytes. We found that nine much smaller deletions that included homologous regions of the N-terminus of mKv1.1 resulted in no functional expression. These differences imply that our results are specific to members of the Shaker subfamily of $\mathrm{K}^{+}$channel genes, and conversely that the results of VanDongen and colleagues may be specific to the Shab subfamily. In this regard, it is interesting to note that the largest C-terminal deletion reported by VanDongen and colleagues left intact 125 residues flanking $\mathrm{S} 6$, the last putative membranespanning domain. The initial 90 residues in this region are well conserved (96\%) among various Shab-like genes (Pak et al., 1991; Hwang et al., 1992). It is therefore possible that a portion of the C-terminus of $\mathrm{K}^{+}$channels encoded by Shab-like genes may be critical for subunit assembly, analogous to the proposed $\mathrm{N}$-terminal domain required for this function in $\mathrm{K}^{+}$channel subunits encoded by Shaker-like genes. The role of transmembrane domains in permitting or directing the assembly of voltage-gated $\mathrm{K}^{+}$channels is unknown. It will be interesting to determine the relative weight of the contributions of the transmembrane domains compared to those of cytoplasmically located domains in the mechanisms that permit and limit assembly of specific $\mathrm{K}^{+}$channel subunits.

Among other membrane proteins, aqueous as opposed to transmembrane domains appear to be critical for mediating subunit assembly. For example, the N-terminus, but not transmembrane domains, is required for assembly of some muscle ACh receptor subunits (Yu and Hall, 1991; Verrall and Hall, 1992). The $\beta$-subunit of the Na,K-ATPase, is thought to possess an $\mathrm{N}$-terminal cytoplasmic domain and a $\mathrm{C}$-terminal ectodomain. The specificity of assembly of the $\beta$-subunit with the $\alpha$-subunit residues in the C-terminal ectodomain of the $\beta$-subunit, but not its transmembrane domain (Renaud et al., 1991). 
There exist other examples of oligomeric membrane proteins in which specific interactions between aqueous domains are required for subunit assembly and stability (Hurtley and Helenius, 1989). Our results suggest that for $\mathrm{K}^{+}$channel subunits encoded by genes from the Shaker subfamily, aqueous domains, especially the $\mathrm{N}$-terminus, play a critical role in channel assembly.

Note added in proof: Since the revision of this manuscript, Shen et al. (Neuron 11:67-76, 1993) have reported data corroborating our finding that the $\mathrm{N}$-terminus plays an important role in the assembly of Shaker-like $\mathrm{K}$ channels.

\section{References}

Armstrong CM, Bezanilla F (1974) Charge movement associated with the opening and closing of the activation gates of the $\mathrm{Na}^{+}$channels. J Gen Physiol 63:533-552.

Benishin CG, Sorenson RG, Brown WE, Krueger BK, Blaustein MP (1988) Four polypeptide components of green mamba venom selectively block certain potassium channels in rat brain synaptosomes. Mol Pharmacol 34:152-159.

Busch AE, Hurst RS, North RA, Adelman JP, Kavanaugh MP (1991) Current inactivation involves a histidine residue in the pore of the rat lymphocyte potassium channel RGK5. Biochem Biophys Res Commun 179:1384-1390.

Chandy GK, Williams CB, Spencer RH, Aguilar BA, Ghanshani S, Tempel BL, Gutaman GA (1990) A family of three mouse potassium channel genes with intronless coding regions. Science 247:973-975.

Christie MJ, North RA, Osborne PB, Douglass J, Adelman JP (1990) Heteropolymeric potassium channels express in Xenopus oocytes from cloned subunits. Neuron 2:405-411.

Covarrubias M, Wei A, Salkoff L (1991) Shaker, Shal, Shab, and Shaw express independent $\mathrm{K}^{+}$current systems. Neuron 7:763-773.

Drewe JA, Verma S, Frech G, Joho RH (1992) Distinct spatial and temporal expression patterns of $\mathrm{K}^{+}$channel mRNAs from different subfamilies. J Neurosci 12:538-548.

Hoshi T, Zagotta WN, Aldrich RW (1991) Two types of inactivation in Shaker $\mathrm{K}^{+}$channels: effects of alterations in the carboxy-terminal region. Neuron 7:547-556.

Hurst RS, Busch AE, Kavanaugh MP, Osborne PB, North RA, Adelman JP (1991) Identification of amino acid residues involved in dendrotoxin block of voltage-dependent potassium channels. Mol Pharmacol 40:572-576.

Hurtley SM, Helenius A (1989) Protein oligomerization in the endoplasmic reticulum. Annu Rev Cell Biol 5:277-307.

Hwang PM, Glatt CE, Bredt DS, Ycllcn G, Snyder SH (1992) A novel $\mathrm{K}^{+}$channel with unique localizations in mammalian brain: molecular cloning and characterization. Neuron 8:473-481.

Isacoff EY, Jan YN, Jan LY (1990) Evidence for the formation of heteromultimeric potassium channels in Xenopus oocytes. Nature 345:530-534.

Ito W, Ishiguro H, Kurosawa Y (1991) A general method for introducing a series of mutations into cloned DNA using the polymerase chain reaction. Gene 102:67-70.

Iverson LE, Rudy B (1990) The role of the divergent amino and carboxyl domains on the inactivation properties of potassium channels derived from the Shaker gene of Drosophila. J Neurosci 10:29032916

Kamb A, Tseng-Crank J, Tanouye MA (1988) Multiple products of the Drosophila Shaker gene may contribute to potassium channel diversity. Neuron 1:421-430.

Kavanaugh MP, Hurst RS, Yakel J, Varnum MD, Adelman JP, North RA (1992) Multiple subunits of a voltage-dependent polassium channel contribute to the binding site for tetraethylammonium. Neuron 8:493-497.
Li M, Jan YN, Jan LY (1992) Specification of subunit assembly by the hydrophilic amino-terminal domain of the Shaker potassium channel. Science 257:1225-1230.

Liman ER, Tytgat J, Hess P (1992) Subunit stoichiometry of a mammalian $\mathrm{K}^{+}$channel determined by construction of multimeric cDNAs. Neuron 9:861-871.

Mackinnon R (1991) Determination of the subunit stoichiometry of a voltage-activated potassium channel. Nature 350:232-235.

Migeon MB, Street VA, Demas VP, Tempel BL (1992) Cloning and characterization of MK6, a purine potassium channel gene. Epilepsy Res [Suppl] 9:173-181.

Miller C (1991) 1990: Annus mirabilis of potassium channels. Science 252:1092-1096.

Noda M, Shimizu S, Tanabe T, Takai T, Kayano T, Ikeda T, Takahashi H, Nakayama H, Kanaoka Y, Minamino N, Kangawa K, Matsu H, Raftery MA, Hirose T, Inayama S, Hayashida H, Miyata T, Numa S (1948) Primary structure of Electrophorus electricus sodium channel deduced from cDNA sequence. Nature 312:121-127.

Pak MD, Covarrubias M, Ratcliffe A, Salkoff L (1991) A mouse brain homolog of the Drosophila Shab $\mathrm{K}^{+}$channel with conserved delayedrectifer properties. J Neurosci 11:869-880.

Pongs O, Kecskemethy N, Muller R, Krah-Jentgens I, Baumann A, Kiltz HH, Canal I, Llamazares S, Ferrus A (1988) Shaker encodes a family of putative potassium channel proteins in the nervous system of Drosophila. EMBO J 7:1087-1096.

Renaud KJ, Inman EM, Fambrough DM (1991) Cytoplasmic and transmembrane domain deletions of $\mathrm{Na}, \mathrm{K}$-ATPase $\beta$-subunit: effects on subunit assembly and intracellular transport. J Biol Chem 266 : 20491-20497.

Ruppersberg JP, Schröter KH, Sakmann B, Stocker M, Sewing S, Pongs O (1990) Heteromultimeric channels formed by rat brain potassium-channel proteins. Nature 345:535-537.

Schwarz TL, Tempel BL, Papazian DM, Jan YN, Jan LY (1988) Multiple potassium-channel components are produced by alternative splicing at the Shaker locus in Drosophila. Nature 331:137-142.

Stocker M, Pongs O, Hoth M, Heinemann SH, Stühmer W, Schroeter $\mathrm{K}-\mathrm{H}$, Ruppersberg JP (1991) Swapping of functional domains in voltage-gated channels. Proc R Soc Lond [Biol] 245:101-107.

Stühmer W, Ruppersberg J, Schröter K, Sakmann B, Stocker M, Giese K, Perschke A, Baumann A, Pongs O (1989) Molecular basis for functional diversity of voltage-gated $\mathrm{K}^{+}$channels in mammalian brain. EMBO J 8:3235-3244.

Swanson R, Marshall J, Smith JS, Williams JB, Boyle MB, Folander $\mathrm{K}$, Luneau CJ, Antanavage J, Oliva C, Buhrow SA, Bennett C, Stein RB, Kaczmarek LK (1990) Cloning and expression of cDNA and genomic clones encoding three delayed rectifer potassium channels in rat brain. Neuron 4:929-939.

Tanabe T, Takeshima H, Mikami A, Flockerzi V, Takahashi H, Kangawa K, Kojima M, Matsuo H, Hirose T, Numa S (1987) Primary structure for the receptor for calcium channel blockers from skeletal muscle. Nature 328:313-318.

Tempel BL, Papazian DM, Schwarz TL, Jan YN, Jan LY (1987) Sequence of a probable potassium channel component encoded at Shaker locus of Drosophila. Science 237:770-775.

Tempel BL, Jan YN, Jan LY (1988) Cloning of a probable potassium channel gene from mouse brain. Nature 332:837-839.

Timpe LC, Schwarz TL, Tempel BL, Papazian DM, Jan YN, Jan LY (1988) Expression of functional potassium channels from Shaker cDNA in Xenopus oocytes. Nature 331:143-145.

VanDongen AM J, Frech GC, Drewe JA, Joho RH, Brown AM (1990) Alteration and restoration of $\mathrm{K}^{+}$channel function by deletions at the $\mathrm{N}$ - and C-termini. Neuron 5:433-443.

Verrall S, Hall ZW (1992) The N-terminal domains of acetylcholine receptor subunits contain recognition signals for the initial steps of receptor assembly. Cell 68:23-31.

Yu X-M, Hall ZW (1991) Extracellular domains mediating $\epsilon$ subunit interactions of muscle acetylcholine receptor. Nature 352:64-67. 